\title{
Thermal and Transport Properties of Mafic and Ultramafic Rocks of Oman Ophiolite
}

\author{
Sayyadul Arafin* and Ram N. Singh
}

\author{
Department of Physics, College of Science, Sultan Qaboos University, P.O. Box: 36, PC 123, \\ Al-Khod, Muscat, Sultanate of Oman. ${ }^{\star} E m a i l:$ sayfin@squ.edu.om.
}

\begin{abstract}
Thermal and other physical properties of rocks and minerals are of considerable significance for deriving mineralogical and compositional models of the Earth's mantle. We have determined these properties for the mafic rock such as gabbro and ultramafic rock like harzburgite of the Oman ophiolite suite by utilizing the Debye characteristic property $\Theta_{D} . \Theta_{D}$ forms the basis of our present investigation and allows us to evaluate their melting temperature $T_{\mathrm{m}}$, thermal conductivity $K_{\mathrm{L}}$ and diffusivity $D$. Their seismic velocities and the density data are used, a priori, to determine the Debye temperature of these rocks. Different thermoelastic and thermodynamic relations are further used to investigate the above properties as a function of temperature, $T$. Our analysis shows that $\Theta_{D}$ is temperature dependent, indicating the presence of vibrational modes other than the Debye distribution in the gabbro and harzburgite of the Oman ophiolite. Results suggest that the thermal properties such as $\Theta_{D}, T_{\mathrm{m}}$ and specific heat capacity $c_{P}$ and transport properties such as $K_{\mathrm{L}}, D$ and viscosity, $\eta$ of ultramafic rock (harzburgite) are higher than those of mafic rock, indicating the influence of an olivine content in the former. $\Theta_{D}$ decreases with increasing temperature but increases with increasing pressure, $P$. Similarly, compressibilities increase for both rocks with increasing $T$ but decrease with increasing $P$. The trends of variation of thermal conductivity and diffusivity with temperature and pressure are opposite. $K_{\mathrm{L}}$ and $D$ decrease with increasing $T$ but are found to increase with increasing $P$.
\end{abstract}

Keywords: Debye temperature; Melting temperature; Specific heat capacity; Thermal conductivity; Diffusivity; Ophiolite.

الخواص الحرارية والانتقالية للصخور القاعدية وفوق القاعدية من الأفويلات العمانية

$$
\text { سيد العارفين و رام سنج }
$$

الملخص: الخواص الحرارية و الفيزيائية للصخور والمعادن لها أهمية واضحة في استنباط النماذج المعدنية والتركيبية للقشرة الأرضية. لقد استخرجنا

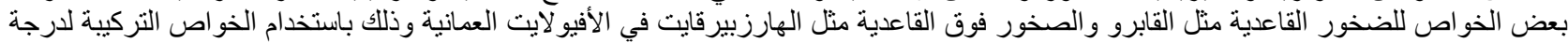

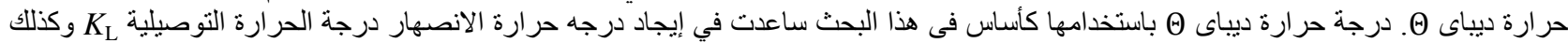

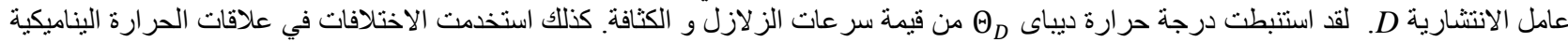

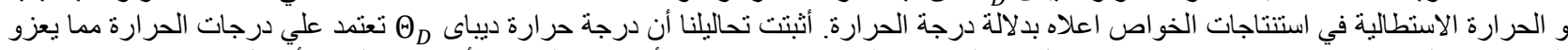

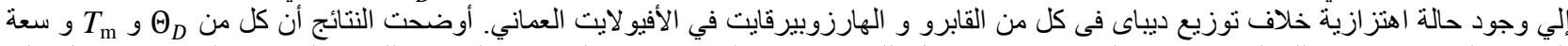

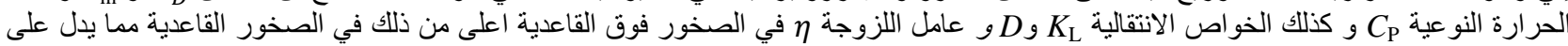
تاثير معدن الأولفين في الصخور فوق القاعدية.

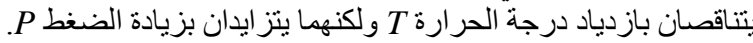

الكلمات المفتاحية: درجة حرارة ديباى ف ، درجة حر ارة الانصهار ، سعة الحرارة النوعية ، درجة الحر ارة التوصيلية ، الأفيو لايت.

\section{Introduction}

$\mathbf{O}^{\prime \prime}$ ur present understanding of the deep interior of the earth in terms of a thin crust, a mantle, a liquid outer core and a solid inner core is largely based on seismologoical data recorded at the network of seismic stations distributed all over the globe. However, thermal properties along with geochemical data have become increasingly important lately in the understanding of the interior of the Earth. They are of considerable significance for deriving the mineralogical and compositional models of the Earth's mantle. At depth levels of less than $700 \mathrm{~km}$, thermophysical properties can help determine the tectonic and petrogenic processes involved in the generation of oceanic lithosphere. Besides providing information on the interior of the Earth, thermoelastic properties can enhance our knowledge about 


\section{SAYYADUL ARAFIN AND RAM N. SINGH}

the formation and transformation of rocks and minerals. The rate of deformation increases strongly with temperature but decreases with pressure at modest pressures. Thermal and transport properties of planetary materials as functions of temperature and pressure are the key to the understanding of the dynamics and evolution of terrestrial planets.

In recent years, a good deal of interest has been shown in the literature [1-6] in the study of the thermal properties of the mantle and the core. The Debye temperature, $\Theta_{D}$, is one of the important ingredients in geophysical studies and has facilitated the characterization of rocks, minerals, and even geological processes such as metamorphism [7]. Any change in the external condition of rocks, and other material formation and transformation, can lead to a change in $\Theta_{D}$. The Debye temperature is a physical constant of matter that characterizes numerous properties of solids, such as specific heat, electric conductivity, thermal conductivity, broadening of X-ray spectral lines, and elastic properties. In Debye theory, $\Theta_{D}$, is the temperature of a crystal's highest normal mode of vibration, i.e. the highest temperature that can be achieved due to a single normal vibration. The concept was first introduced by Peter Debye in his theory of specific heat. The Debye temperature is defined by the equation, $\Theta_{D}=h v_{D} / k$, where $k$ is Boltzmann's constant, $h$ is Planck's constant, and $v_{D}$ is the maximum frequency of the vibrations of the atoms of a solid. It gives a relative idea for a temperature scale, above which vibrations within a solid behave basically according to the Dulong-Petit law and the heat capacity is given by $3 R, R$ being the gas constant. Below the Debye temperature quantum effects are important, and the heat capacity is reduced considerably at low temperatures. At $T \ll \Theta_{D}$, the specific heat is proportional to $\left(T / \Theta_{D}\right)^{3}$ (the Debye $T^{3}$ approximation).

The difference between the Debye temperatures of the separated facies of the metamorphic rocks is maximum in the case of regional metamorphism, is lower at an intermediate level of metamorphism, and is a minimum in the case of extremely altered rocks. Similarly, melting temperature and its pressure dependence, $T_{\mathrm{m}}(\mathrm{P})$, are important items of information required for the thermal characterization of materials, including minerals and rocks. On the other hand, the dependence of thermal and transport properties on temperature and pressure is important information on the physical properties of rocks for understanding the driving forces in geodynamics.

In the present work we have used the seismic velocity and the density data $[8,9]$ to obtain useful properties such as Debye temperature, melting temperature, compressibilities, specific heat capacities, Gruneisen parameter, viscosity, thermal conductivity and diffusivity of harzburgite and gabbro by making use of thermoelastic and thermodynamic equations. Gabbro and harzburgite rock (a type of peridotite rock) of the Oman ophiolite are of considerable interest to geophysicists and geologists. The available measured density and seismic velocities of these rocks, which are the basic input of the present analysis, are uniform and consistent.

A brief description of the relevant rocks of the Oman ophiolite is given in section 2. Section 3 discusses the basic formalism for determining the temperature dependence of Debye temperature, specific heats, compressibilities and diffusivity. The melting criterion and viscosity are discussed in section 4. Section 5 describes the pressure dependence of thermal properties, and is followed by a summary and conclusion in Section 6.

\section{Oman Ophiolite}

Ophiolite is an integral part of many mountain belts. Study of ophiolites aids in understanding the formation of mountains and the history of sea-floor spreading [10,11] in past ocean basins. The Samail ophiolite in southeastern Oman (see Figures 1 and 2 [12,13] ) provides the best opportunity [14] to investigate the oceanic lithosphere exposed on land. From base to top, the Oman ophiolite sequence is made up of peridotite, layered gabbro, massive gabbro, dikes and volcanic rocks. The entire sequence is about $13 \mathrm{~km}$ thick. Harzburgite forms the bottom-most rock of the Oman ophiolite, which is a sequence of rocks representing oceanic crustal and upper mantle material that has been pushed up onto the continents. Olivine is the major constituent mineral of the upper mantle, with an average composition of $90 \% \mathrm{~mol} \mathrm{Mg}_{2} \mathrm{SiO}_{4}$ and $10 \%$ mol Fe $\mathrm{SiO}_{4}$ [10]. About $80 \%$ of the harzburgite of the Oman ophiolite suite is olivine. The thermoelastic properties of harzburgite will, therefore, provide us with a better understanding of the composition and dynamics of the upper mantle. Harzburgite is a type of peridotite rock, abundantly found in the upper mantle and predominantly composed of the minerals olivine and orthopyroxene, and relatively low proportions of basaltic ingredients. It has a uniform mineralogy of $80 \%$ olivine $\left((\mathrm{Fe}, \mathrm{Mg})_{2} \mathrm{SiO}_{4}\right), 17-19 \%$ orthopyroxene $((\mathrm{Mg}$, $\left.\mathrm{Fe})_{2} \mathrm{Si}_{2} \mathrm{O}_{6}\right), 1 \%$ chrome spinel $\left((\mathrm{Mg}, \mathrm{Fe})(\mathrm{Al}, \mathrm{Cr})_{2} \mathrm{O}_{4}\right)$ and $1 \%$ clinopyroxene $\left((\mathrm{Ca}, \mathrm{Mg}, \mathrm{Fe}, \mathrm{Al})_{2}(\mathrm{Si}, \mathrm{Al})_{2} \mathrm{O}_{6}\right)$.

Gabbro, an igneous rock, is another major constituent of the Oman ophiolite suite. The gabbroic layer is interlayered between the mantle peridotite and the sheeted dyke complex. It represents the crustal succession of the Oman ophiolite with a thickness ranging from about $1.5 \mathrm{~km}$ to $4 \mathrm{~km}$. It is believed to have been generated in a magma chamber beneath an ancient fast-spreading ocean ridge. The largest part of the gabbroic layer is composed of troctolite, olivine gabbro and gabbro with minor wehrlite and dunite. Gabbro is mainly composed of calcium plagioclase, pyroxene and olivine minerals. The percentage of olivine present in the gabbro of the Oman ophiolite ranges from $18 \%$ to $44 \%$ [15]. 


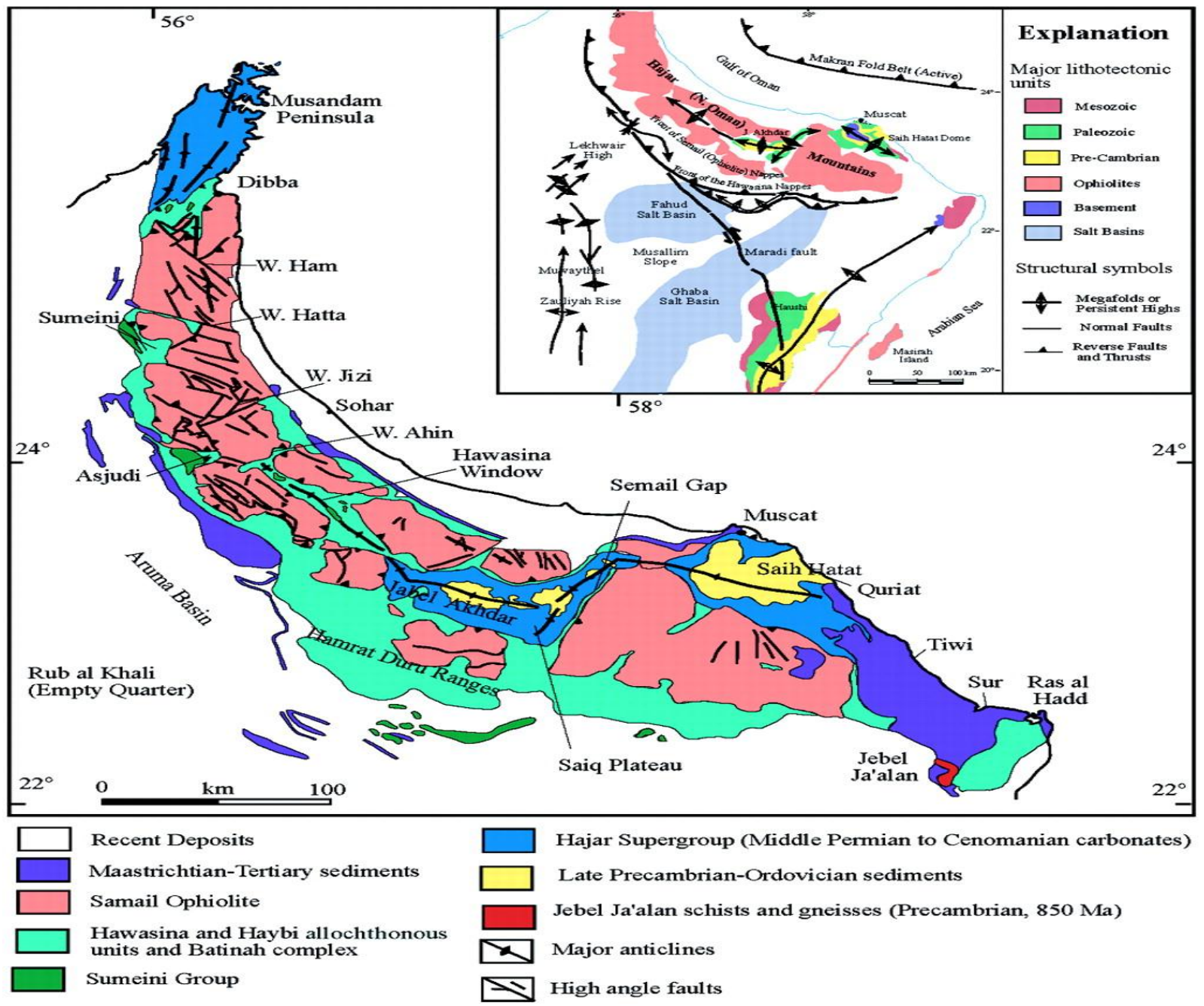

Figure 1. Geology of Oman showing Semail ophiolite in pink [12]

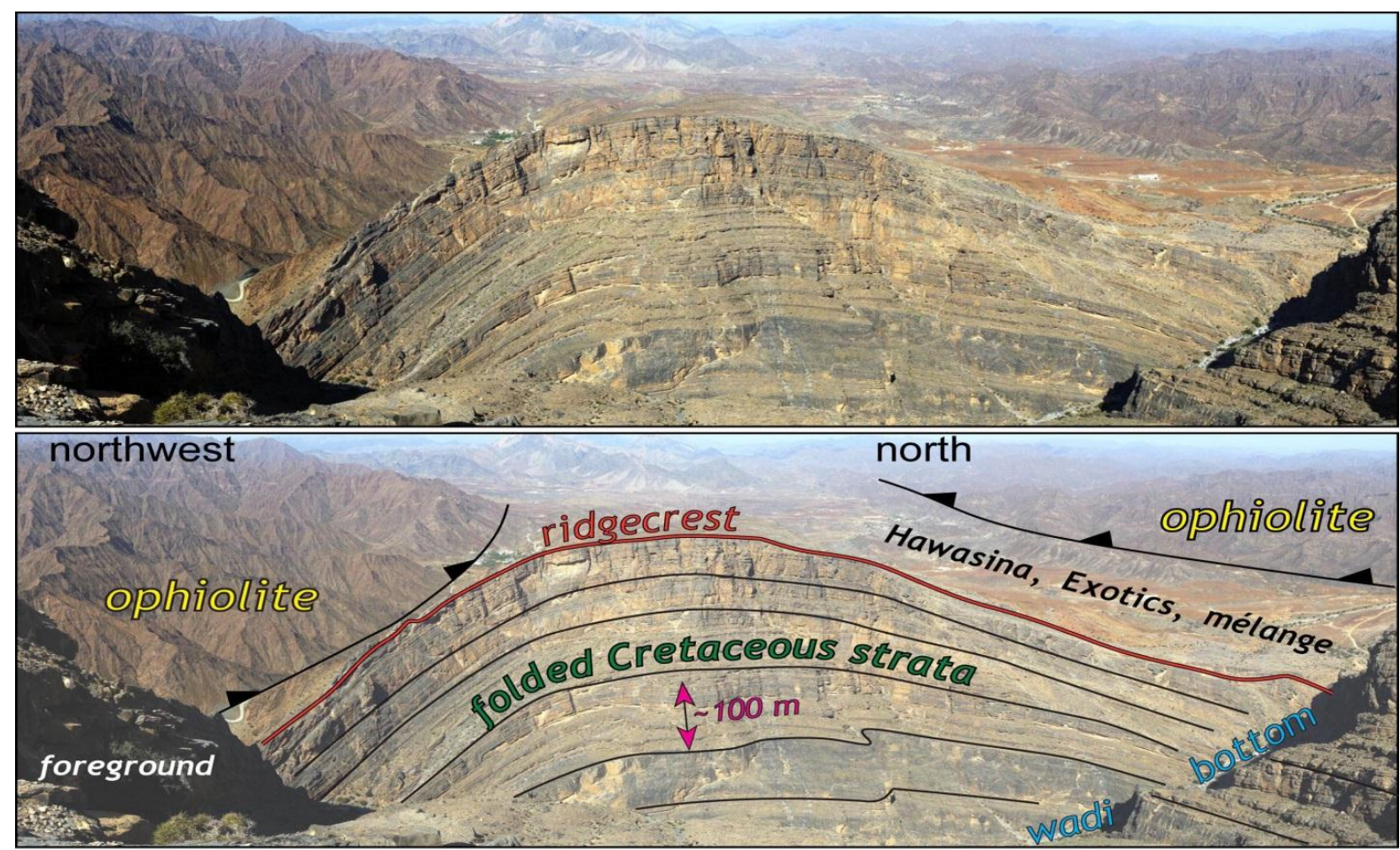

Figure 2. Exposed rocks of the Oman ophiolite and its associates [13] 


\section{Temperature Dependence of Thermophysical Properties}

\subsection{Debye Temperature}

The Debye theory connects the heat capacity of a poly-atomic solid with its elastic constants, and paves the way for calculating the characteristic temperature from the measured data of density and velocities of primary ( $p$-wave) and secondary or shear (s-wave) ultrasonic waves in the solid. Here we have used acoustical data [8] to obtain Debye temperature. In terms of acoustic velocities, $\Theta_{D}$, also known as acoustic Debye temperature in geophysical literature, takes the simplified form [16]:

$$
\Theta_{D}(T)=251.2\left(\frac{\rho(T)}{\mu(T)}\right)^{1 / 2} v_{m}(T)
$$

$\rho$ is the density $\left(\mathrm{g} \mathrm{cm}^{-3}\right)$ and $\mu$ is the mean atomic mass given by $M / p ; M$ is the molecular weight $\left(\mathrm{g} \mathrm{mol}^{-1}\right)$ and $p$ is the atomic number. For composite materials like harzburgite and gabbro, the mean atomic mass, $\mu$ is taken as 21 $\mathrm{g} \mathrm{mol}^{-1}[17] \cdot v_{m}$ is the generalized mean velocity $\left(\mathrm{km} \mathrm{s}^{-1}\right)$ given by:

$$
v_{m}(T)=\left[\frac{1}{3}\left(v_{p}^{-3}(T)+2 v_{s}^{-3}(T)\right)\right]^{-1 / 3}
$$

where $v_{\mathrm{p}}$ and $v_{\mathrm{s}}$ are the acoustic velocities of the primary (longitudinal) and secondary (transverse) waves. We have used experimentally determined values of $v_{\mathrm{p}}, v_{\mathrm{s}}, \rho$ and an empirical value of mean atomic mass 21 amu in Eqs. (1) and (2) to calculate $\Theta_{\mathrm{D}}[8,9]$.

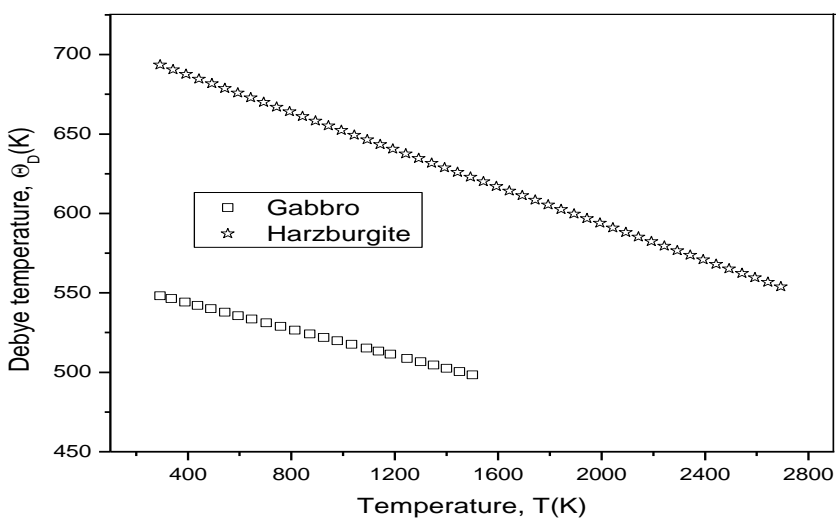

Figure 3: Variation of Debye temperature $\left(\Theta_{D}\right)$ of gabbro and harzburgite with temperature

We have calculated the temperature dependence of density and velocity of the mafic and ultramafic rocks from the available data $[8,9]$. The values of $\Theta_{D}$ obtained at different temperatures of gabbro and harzburgite are plotted in Figure 3, which shows that $\Theta_{D}$ decreases linearly with increasing temperature of the rock. Typical values of $\Theta_{D}$ at room temperature $(293.15 \mathrm{~K})$ for gabbro and harzburgite are found to be $548 \mathrm{~K}$ and $693 \mathrm{~K}$. $\Theta_{D}$ for harzburgite is about $26 \%$ higher than that of gabbro. The higher value for harzburgite may be due to the abundance of olivine in it.There are hardly any data on $\Theta_{D}$ of these rocks availalable in the literature. It may be recalled that gabbro and harzburgite are composed of $40 \%$ and $80 \%$ olivine respectively. $\Theta_{D}$ for olivine is found to be $731 \mathrm{~K}$ [18]. In view of this, the computed $\Theta_{D}$ for gabbro and harzburgite are well within the expected range.

\subsection{Specific Heat as a Function of Temperature}

The Debye theorywas originally developed for monatomic solids for which the vibrational phonon density of states is given by Debye frequency spectrum. The theory can be applied to polyatomic solids like rocks and minerals provided the density of states can be approximated by the frequency spectrum[19]. Taking into account all the possible modes of acoustic vibrations, the total phonon energy, $U_{D}$ becomes [19] :

$$
U_{D}=9 N k_{B} T\left(\frac{T}{\Theta_{D}}\right)^{3} \int_{0}^{x_{D}} \frac{x^{3} d x}{\left(e^{x}-1\right)}
$$

The upper limit of integration, $x_{D}$ refers to:

$$
x_{D}=\frac{h \omega_{D}}{2 \pi k_{B} T}
$$

where $h$ is the Planck's constant, $\omega_{D}$ is the Debye angular frequency and $k_{B}$ is the Boltzmann's constant. Differentiating Eq. (3) with respect to $T$, one obtains specific heat at constant volume: 


$$
c_{V}=9 N k_{B}\left(\frac{T}{\Theta_{D}}\right)^{3} \int_{0}^{x_{D}} \frac{x^{4} e^{x} d x}{\left(e^{x}-1\right)^{2}}
$$

The integral has been evaluated here numerically by using the value of $\Theta_{D}(=548 \mathrm{~K})$ as determined in section 3.1. A plot of $c_{V}$ against the ratio, $T / \Theta_{D}$ is shown in Figure 4. The curve approaches the maximum value of $25 \mathrm{Jmol}^{-1} \mathrm{~K}^{-1}$ at higher temperatures, which is the highest limiting value of $3 R$ ( $R$ being the gas constant) due to Dulong Petit'slaw. At low temperature $\left(T<\Theta_{D}\right), C_{V}$ increases with increasing temperature as per Debye's $T^{3}$ law.

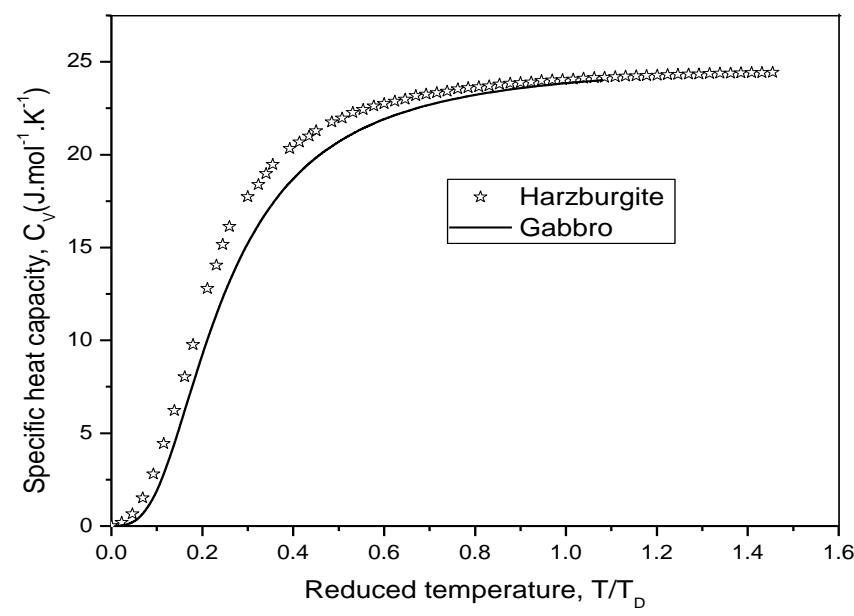

Figure 4. The computed values of the Debye specific heat $\left(c_{V}\right)$ of gabbro and harzbutgite plotted against $\mathrm{T} / \Theta_{D}$

\subsection{Compressibilities}

\subsubsection{Isothermal and Adiabatic Compressibilities}

Specific heat capacities are related to isothermal compressibility, $\kappa_{T}$ and the coefficient of volume expansion, $\beta$ through a thermodynamic relation:

$$
c_{P}=c_{V}+\frac{T V \beta}{\kappa_{T}}
$$

Specific heats and compressibilities are also related as:

$$
\gamma=\frac{c_{P}}{c_{V}}=\frac{\kappa_{T}}{\kappa_{S}}
$$

where $\kappa_{S}$ is the isentropic compressibility. From Eqs. (6) and (7) one has:

$$
\gamma=1+\frac{T V \beta^{2}}{c_{P} \kappa_{S}}
$$

$\kappa_{S}$ and $\kappa_{T}$ minerals have been determined here from acoustic data. The adiabatic compressibility $\kappa_{S}$ is determined [20] from the measured values of density ( $\rho$ ), and longitudinal (vp) and transverse (vs) velocities by using the relation:

$$
\kappa_{S}(T)=\frac{1}{\rho(T)\left[v_{l}^{2}(T)-\frac{4}{3} v_{t}^{2}(T)\right]}
$$

Further, the isothermal compressibility, $\kappa_{T}$ is related to Poisson ratio $\sigma$, density $\rho$ and p-wave velocity $v_{p}$ by the equation:

$$
\kappa_{T}(T)=\frac{3[1-\sigma(T)]}{[1+\sigma(T)] \rho v_{p}^{2}}
$$

where $\sigma$ is expressed in terms of the two velocities by the equation:

$$
\sigma(T)=\frac{\left[v_{l}^{2}(T)-2 v_{t}^{2}(T)\right]}{2\left[v_{l}^{2}(T)-2 v_{t}^{2}(T)\right]}
$$

The computed values of $\kappa_{S}$ and $\kappa_{T}$ for gabbro and harzburgite are plotted in Figures 5 and 6, respectively, as functions of temperature. $\kappa_{S}$ and $\kappa_{T}$ are found to increase with increasing temperature. $\kappa_{T}$ is slightly higher than $\kappa_{S}$. At room temperature the difference between $\kappa_{S}$ and $\kappa_{T}$ is small, but the difference increases with increasing temperature. $\gamma$ is determined using the values of $\kappa_{S}$ and $\kappa_{T}$ in Eq. (7). It is found to be 1.009296 and exhibits very 
little dependence on temperature. The results given in Figures 5 and 6 suggest that $\kappa_{S}$ and $\kappa_{T}$ of gabbro are higher than those of harzburgite. At ambient condition, $\kappa_{S}$ of gabbro is $36 \%$ higher than that of harzburgite.

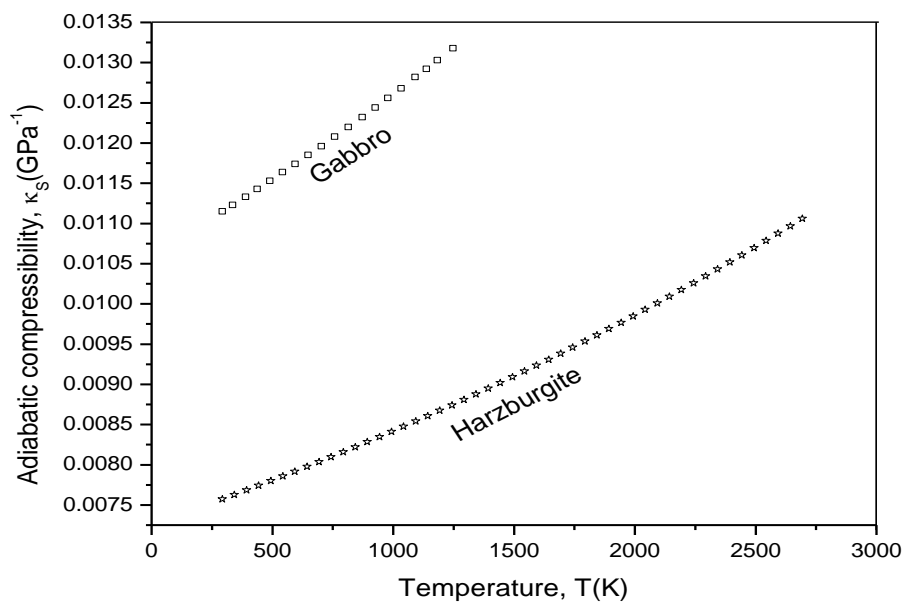

Figure 5. Comparison of of temperature dependent adiabatic $\left(\kappa_{S}\right)$ compressibility of gabbro and harzburgite

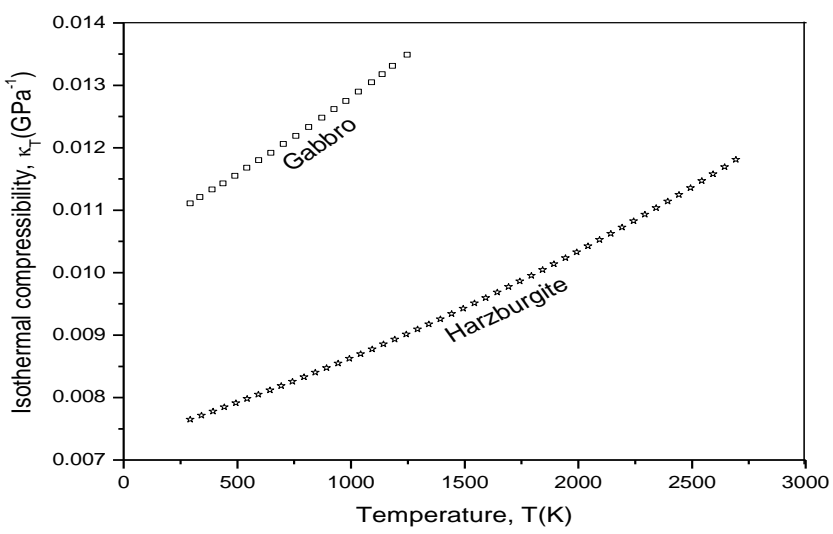

Figure 6. Comparison of of temperature dependent isothermal $\left(\kappa_{T}\right)$ compressibility of gabbro and harzburgite

\subsubsection{Specific Heat at Constant Pressure from Thermodynamic Relations}

It may be noted that $\gamma$ for most solid rocks is very close to unity. $\gamma$ is used in Eq. 8 to determine $c_{P}$. The thermodynamic values of $c_{P}$ for mafic rock (gabbro) and ultramafic rock (harzburgite) are calculated as 678.1 and $795.7 \mathrm{~J} \mathrm{~kg}^{-1} \mathrm{~K}^{-1}$ respectively at room temperature of $293.15 \mathrm{~K}$. This yields the specific heat at constant volume, $c_{V}$ as $671.0 \mathrm{~J} \mathrm{~kg}^{-1} \mathrm{~K}^{-1}$ for gabbro and $787.5 \mathrm{~J} \mathrm{~kg}^{-1} \mathrm{~K}^{-1}$ for harzburgite. These values are in very good agreement with the measured values [21] of $650 \mathrm{~J}^{-\mathrm{kg}^{-1}} \cdot \mathrm{K}^{-1}$ for gabbro and $771 \mathrm{~J} \mathrm{~kg}^{-1} \mathrm{~K}^{-1}$ for harzburgite. In the case of gabbro a variation in specific heat capacity value of $650-1000 \mathrm{~J} \mathrm{~kg}^{-1} \mathrm{~K}^{-1}$ is reported [21]. By using the value of mean atomic mass of 21.0 amu, $c_{P}$ and $c_{V}$ reduce to 14.24 and $14.1 \mathrm{~J} \mathrm{~mol}^{-1} \mathrm{~K}^{-1}$ for gabbro and 16.71 and $16.54 \mathrm{~J} \mathrm{~mol}^{-1} \mathrm{~K}^{-1}$ for harzburgite respectively. We may recall that, from Debye theory, $c_{V}$ at room temperature has been computed to be 21.1 for mafic and $19.1 \mathrm{~J} \cdot \mathrm{mol}^{-1} \cdot \mathrm{K}^{-1}$ for ultramafic rocks, figures which are about $50 \%$ and $15.5 \%$ higher than the thermodynamic values. The difference increases at higher temperatures. It was argued [17] that the similarity between heat capacities obtained thermodynamically and from Debye theory can be used as a criterion for a material to be classified as a Debye-like solid. We can see that the two values are far from being close to each other, indicating that the mafic and ultramafic rocks of Oman ophiolite are not Debye-like solids.

\subsection{Thermal Conductivity}

From the striking linearity of a plot of $\Theta_{\mathrm{D}}$ against $K_{\mathrm{L}}$ for silicate minerals, an empirical relation has been proposed by Horai and Simmons [22] connecting the two as:

$$
K_{L}(T)=0.0164 \Theta_{D}(T)-6.292
$$




\section{THERMAL AND TRANSPORT PROPERTIES OF MAFIC AND ULTRAMAFIC ROCKS}

where $K_{\mathrm{L}}$ is measured in $\mathrm{W} \mathrm{m}^{-1} \mathrm{~K}^{-1}$ and $\Theta_{D}$ in $K$. Although the above equation was proposed for silicate minerals, the effect of chemical composition was taken into consideration in establishing Eq. (12), and hence, it has been suggested [22] that it can be applied to a wide range of materials. Equation (12) can be used for evaluating $K_{\mathrm{L}}$, provided $\Theta_{D}$ is known. The thermal conductivity for gabbro determined from Eq. (12) is found to be $2.68 \mathrm{~W} \mathrm{~m}^{-1} \mathrm{~K}^{-1}$, which compares well with the measured value of $2.47 \mathrm{~W} \mathrm{~m}^{-1} \mathrm{~K}^{-1}$ [23], while it is $5.07 \mathrm{~W} \mathrm{~m}^{-1} \mathrm{~K}^{-1}$ for harzburgite which is higher than the value $2.69 \mathrm{~W} \mathrm{~m}^{-1} \mathrm{~K}^{-1}$ reported in [23]. Rocks of similar genesis may have quite different thermophysical properties because of their origin from different geological provinces and their different ages [24].

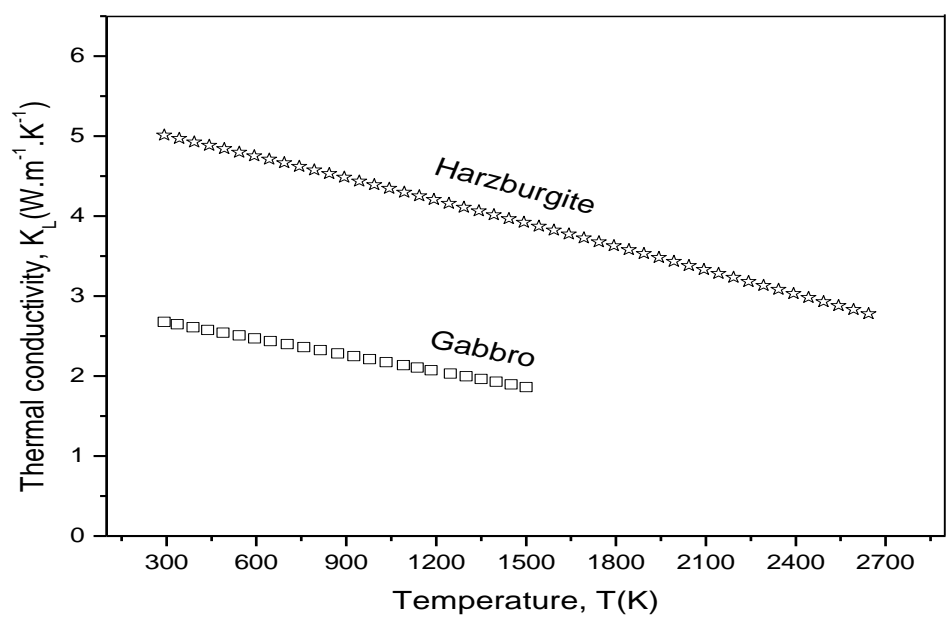

Figure 7. Dependence of thermal conductivities of gabbro and harzburgite on temperature

According to Wiedemann-Franz law the ratio of the thermal conductivity, $K_{\mathrm{L}}$ to the electrical conductivity, $\sigma$ is given by:

$$
\frac{K_{L}}{\sigma}=L T
$$

where $\sigma$ is the electrical conductivity and $L=2.45 \times 10^{-8} \mathrm{~W} \Omega \mathrm{K}^{-2}$ is the Lorentz constant. This yields the electrical conductivity for gabbro, $\sigma_{\text {gabbro }}=3.619 \times 10^{5} \mathrm{SI} \mathrm{m}^{-1}$ and for harzburgite, $\sigma_{\text {harzburgite }}=6.186 \times 10^{5} \mathrm{SI} \mathrm{\textrm {m } ^ { - 1 }}$ at normal temperature $300 \mathrm{~K}$. Our results of $K_{L}$ and $\sigma$ suggest that harzburgite is a better conductor for heat and electricity than gabbro.

\subsection{Thermal Diffusivity and Activation Energy}

In the heat transfer analysis, thermal diffusivity, $D$ plays an important role which measures the ability of a material to conduct thermal energy relative to its ability to store thermal energy. It is defined as the ratio of the thermal conductivity, $K_{\mathrm{L}}$ to the product of the density, $\rho$ and the specific heat capacity, $c_{P}$, i.e.:

$$
D(T)=\frac{K_{L}(T)}{\rho(T) c_{P}(T)}
$$

where $K_{\mathrm{L}}$ is the lattice thermal conductivity, $c_{P}$ is the specific heat capacity at constant pressure, and $\rho$ is the density. The magnitude of thermal diffusivity dictates how fast heat moves through a material. We have used our determined values of $K_{L}(T), c_{P}(T)$ and $\rho(T)$ to determine temperature dependence of the diffusivity. The thermal diffusivity value of the ultramafic rock (harzburgite) determined in this study is $2.15 \mathrm{~mm}^{2} \mathrm{~s}^{-1}$ which is close to the measured value of peridotite (also a an ultramafic rock and similar to harzburgite in composition) from Oman ophiolite is $2.27 \mathrm{~mm}^{2} \mathrm{~s}^{-1}$ [24]. The thermal diffusivity value of $1.3 \mathrm{~mm}^{2} \mathrm{~s}^{-1}$ determined here for the mafic rock (gabbro) is slightly higher than the experimental value of $0.97 \mathrm{~mm}^{2} \mathrm{~s}^{-1}[21] . D(\mathrm{~T})$ of both mafic and ultramafic rocks fall with increasing temperature. The decrease in $D(\mathrm{~T})$ for ultramafic rock is much sharper that of gabbro in the lower range of temperature. At high $T$, $D(\mathrm{~T})$ tends towards a constant value. 


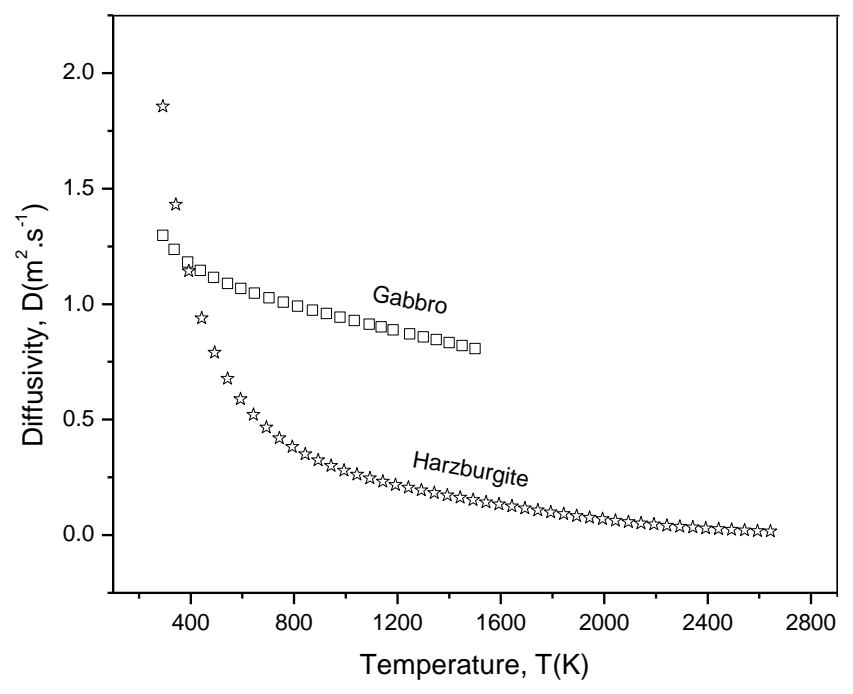

Figure 8. Dependence of diffusivities of gabbro and harzburgite on temperature

The formation of mafic and ultramafic rocks at the deep interior of the Earth involves complex chemical reactions and phase changes under the influence of high temperature and pressure. The activation energy $\Delta \mathrm{E}$ is a measure of the energy necessary for a chemical reaction to occur. The repulsive energy emerging due to the overlap of electron clouds needs to be overcome by the activation energy. The computed values of $D(\mathrm{~T})$ have been fitted to as Arrhenius type equation,

$$
D=D_{0} e^{-\Delta E / R T}
$$

where $R$ is the gas constant. Taking the natural logarithm, one has:

$$
\ln D=\ln D_{0}+\left(-\frac{\Delta E}{R}\right) \frac{1}{T}
$$

The plot of $\ln D$ vs $1 / T$ results in a linear variation. The slope has been used to determine $\Delta \mathrm{E}$. For gabbro $\Delta \mathrm{E}$ is found to be $1.4 \mathrm{~kJ}$ which is much lower than that $(4.3 \mathrm{~kJ})$ of harzburgite.

\section{Melting Temperature and Viscosity}

\subsection{Melting Criterion}

We suggest a simple approach to determine the melting temperature from the knowledge of the Debye temperature, $\Theta_{D}$, which we obtained in section 3.1. Lindemann [25] proposed that the amplitude of the atomic vibrations increase with increasing temperature and that melting occurs when the amplitude of vibrations reach a critical fraction, $y_{m}$ of the mean atomic radius, $R_{a}$. Mott and Jones [20] used the Debye model to show that the mean square amplitude of vibration of each atom is given by $\left(\frac{3 h}{2 \pi \Theta_{D}}\right)^{2}\left(\frac{T}{M k_{B}}\right)^{1 / 2}$ approximately. Using this expression, Lindemann's formula can be written [26]:

$$
T_{m}=\left(\frac{2 \pi}{3 h} y_{m} R_{m} \Theta_{D}\right)^{2} M k_{B}
$$

where $y_{m}$ is the maximum amplitude of vibration [27] which is taken as $0.2 . \Theta_{D}$ is the Debye temperature $(\mathrm{K}), R_{m}$ the mean atomic radius and $M$ the mean atomic mass. The value of $M$ is taken 21 amu for gabbro and harzburgite. $k_{B}$ is the Boltzmann's constant and $h$ is the Planck's constant. The mean atomic radius is calculated from the relation:

$$
R_{m}=\left(\frac{3 M}{4 \pi \rho}\right)^{1 / 3}
$$

The melting temperature of gabbro and harzburgite calculated from the above relations are $1201 \mathrm{~K}$ and $1695 \mathrm{~K}$, which are much higher than the corresponding Debye temperatures, $548 \mathrm{~K}$ and $693 \mathrm{~K} . T_{m}$ is, in general, sensitive to the values of $R_{m}, \Theta_{D}$ and $y_{m}$ as can be seen from Eq. (17). 


\section{THERMAL AND TRANSPORT PROPERTIES OF MAFIC AND ULTRAMAFIC ROCKS}

\subsection{Viscosity}

The viscosity, $\eta_{m}$ of gabbro and harzburgite at their melting points can be determined $[27,28]$ from the values of $M, T_{\mathrm{m}}$ and $V_{m}$ i.e.

$$
\eta_{m}=1.6 \times 10^{-4} \frac{\left\{M T_{m}\right\}^{1 / 2}}{V_{m}^{2 / 3}}
$$

where viscosity, $\eta_{m}$ is given in $\mathrm{mPa}$ s. $V_{m}$ is the atomic volume at melting and $M$ is the molecular weight. Equation (19) is found to reproduce the experimental viscosity data for liquid metals at their melting points with great success. We have collected the values, $\Theta_{D}, T_{\mathrm{m}}, c_{V}, \boldsymbol{K}_{L}, D$ and $\eta$ determined in this work at normal $T$ and $P$ in Table 1 . The viscosity values for the melting phase of gabbro and harzburgite determined from Eq. (19) are found to be $2.21 \mathrm{mPa} \mathrm{s}$ and $2.63 \mathrm{mPa}$ s.at their corresponding melting points $(1201 \mathrm{~K}$ and $1695 \mathrm{~K})$ respectively. It may be noted that all the values of thermal properties of harzburgite are larger than those of gabbro except for thermal conductivity.

Table 1. Debye temperature $\boldsymbol{\Theta}_{\boldsymbol{D}}(\mathrm{K})$, melting temperature $\boldsymbol{T}_{\boldsymbol{m}}(\mathrm{K})$, specific heat capacity $\boldsymbol{c}_{\boldsymbol{P}}\left(\mathrm{J} \mathrm{kg}^{-1} \mathrm{~K}^{-1}\right)$, thermal conductivity $\boldsymbol{K}_{L}\left(\mathrm{~W} \mathrm{~m}^{-1} \mathrm{~K}^{-1}\right)$, diffusivity $D\left(\mathrm{~mm}^{2} \mathrm{~s}^{-1}\right)$ and viscosity $\eta(\mathrm{mPa} \mathrm{s})$ of gabbro and harzburgite; published values for each rock are shown in bracket.

\begin{tabular}{|c|c|c|c|c|c|c|}
\hline Pocks & $\begin{array}{c}\boldsymbol{\Theta}_{\boldsymbol{D}} \\
(\mathrm{K})\end{array}$ & $\begin{array}{c}\boldsymbol{T}_{\boldsymbol{m}} \\
(\mathrm{K})\end{array}$ & $\begin{array}{c}\boldsymbol{c}_{\boldsymbol{P}} \\
\left(\mathrm{J} \mathrm{kg}^{-1} \mathrm{~K}^{-1}\right)\end{array}$ & $\begin{array}{c}\boldsymbol{K}_{\boldsymbol{L}} \\
\left(\mathrm{W} \mathrm{m}^{-1} \mathrm{~K}^{-1}\right)\end{array}$ & $\begin{array}{c}D \\
\left(\mathrm{~mm}^{2} \mathrm{~s}^{-1}\right)\end{array}$ & $\begin{array}{c}\boldsymbol{\eta} \\
(\mathrm{mPa} \mathrm{s})\end{array}$ \\
Gabbro & 548 & 1201 & 678.0 & 2.66 & 1.30 & 0.00221 \\
& & $1123^{[9]}$ & $650.0^{[21]}$ & $2.47^{[21]}$ & $0.97^{[21]}$ & \\
Harzburgite & 693 & 1693 & 796.0 & 5.07 & 1.8 & 0.00263 \\
& $731^{[18]^{* * *}}$ & $2163^{*}, 1473^{\$}$ & $771^{[21]}$ & $2.69^{[21]}$ & $2.27^{[24]}$ &
\end{tabular}

*Melting temperature of $\mathrm{Mg}_{2} \mathrm{Sio}_{4} ;{ }^{\$}$ Melting temperature of $\mathrm{Fe}_{2} \mathrm{SiO}_{4}$. It may be noted that for our model $\mathrm{Mg}_{2} \mathrm{Sio}_{4}$ constitutes $90 \%$ of olivine, which is about $80 \%$ of Oman harzburgite. $\mathrm{Fe}_{2} \mathrm{SiO}_{4}$ constitutes about $10 \%$ of olivine.

** Debye temperature of olivine

\section{Pressure Dependence of Thermal Properties of Gabbro}

The pressure dependence of Debye temperature, specific heat capacity, adiabatic compressibility, isothermal compressibility, thermal conductivity, and diffusivity can be determined from the various equations developed in the previous sections, provided that the pressure dependence data for density and seismic velocities are known. The basic input data (seismic velocities) available for gabbro are taken from reference [8]. The sample of gabbro for which these measurements exist was taken from a depth of $5.5 \mathrm{~km}$. There are no pressure dependent velocity data available for harzburgite in the literature. In this section, we have therefore restricted our discussions of pressure dependent properties to those of gabbro only.

\subsection{Pressure Dependence of Density and Velocity}

The pressure dependence of the densities of gabbro and harzburgite are determined using the Murnaghan equation [29]:

$$
\rho(P)=\rho_{0}\left[1+\frac{b_{1} P}{3 B_{0}}\right]^{1 / n}
$$

where $\rho_{0}$ is the density at atmospheric pressure, $B_{0}$ the bulk modulus, $b_{1}$ the pressure gradient of $B_{0}$ and $P$ the pressure. The pressure dependent density and velocity data of gabbro are plotted in Figs. 9 and 10. The density data show a linear relationship but the velocity data show a non-linear relationship with pressure. 


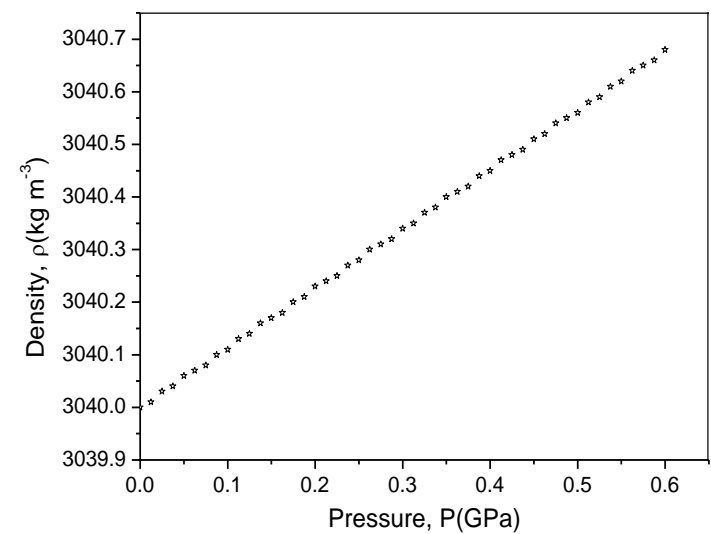

Figure 9. Plot of density of gabbro as a function of pressure

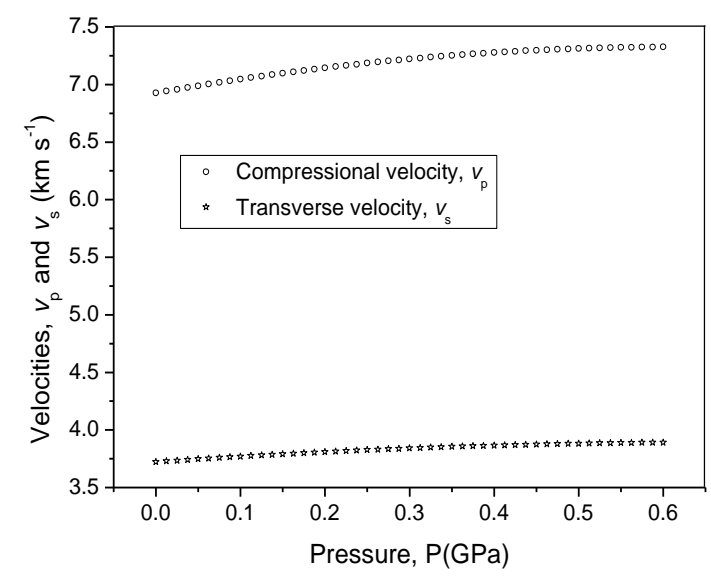

Figure 10. Variation of longitudinal and transverse wave velocity of gabbro with pressure

\subsection{Numerical Results for Debye Temperature, Compressibilities, Specific Heat Capacity, Thermal Conductivity and Diffusivity as a Function of Pressure}

The pressure dependence of Debye temperature, specific heat capacity, compressibilities, thermal conductivity, and diffusivity are plotted in Figures 11-15. The value of $\Theta_{D}$ of gabbro increases from its value of $548 \mathrm{~K}$ at ambient temperature and pressure to a value of $574 \mathrm{~K}$ at $0.60 \mathrm{GPa}$. It can be seen from Figure 11 that $\Theta_{\mathrm{D}}$ increases with increasing $P$ but does not exhibit a linear variation like $\Theta_{D}-T$ variation as found in Figure 3. At high pressures, the gradient $d \Theta_{D} / d P$ is much smaller than that at low pressures. It is expected to be lower at higher pressures bcause various vibrational modes are likely to be compressed resulting in a lower gradient of $d \Theta_{D} / d P$.

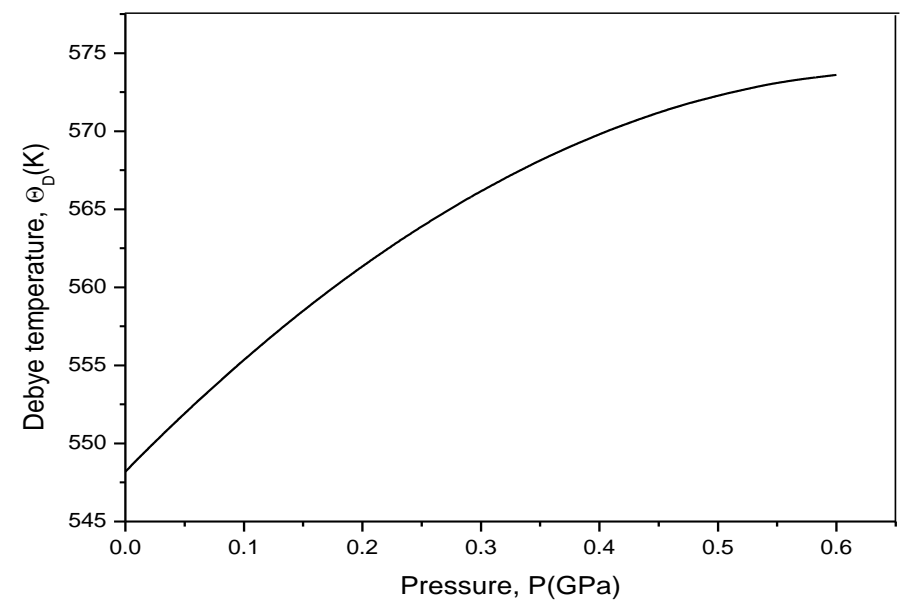

Figure 11. Variation of Debye temperature $\left(\Theta_{D}\right)$ of gabbro with pressure.

The pressure dependence of specific heat capacity, $c_{V}$, is shown in Figure 12. It is determined from Eq. (5) using the values of $\Theta_{D}(\mathrm{P})$ as shown in Figure 11. With increasing pressure, $c_{V}$ decreases nonlinearly from its value of $21.1 \mathrm{~J}$ $\mathrm{mol}^{-1} \mathrm{~K}^{-1}$ at ambient pressure to about $19.6 \mathrm{~J} \mathrm{~mol}^{-1} \mathrm{~K}^{-1}$ at a pressure of $0.6 \mathrm{GPa}$. This amounts to a decrease of $c_{V}$ by $7.5 \%$. 


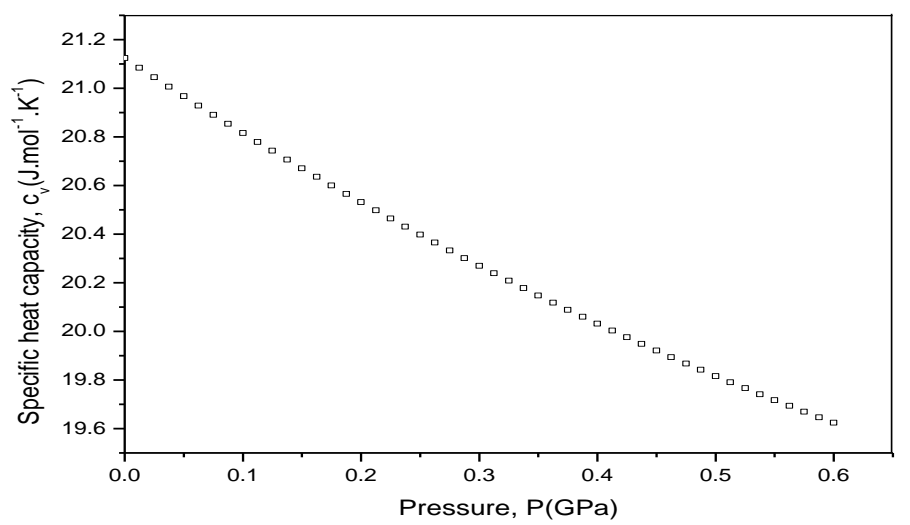

Figure 12. Variation of specific heat capacity, $c_{V}$, of gabbro as a function of pressure.

The computed values of $\kappa_{S}$ and $\kappa_{T}$ are plotted in Figure 13 as a function of $P . \kappa_{S}$ is approximately equal to $\kappa_{T}$ at ambient conditions but the difference between them increases as $P$ increases. $\kappa_{S}$ is smaller than $\kappa_{T}$ at high $P$ which suggests that the specific heat ratio, $\gamma$, slowly increases with increasing pressure.

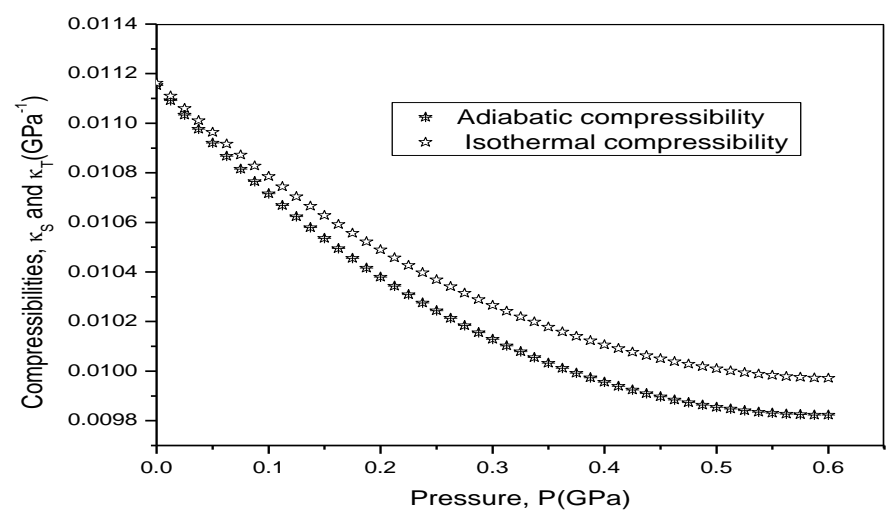

Figure 13. Adiabatic and isothermal compressibilities of gabbro shown as a function of pressure.

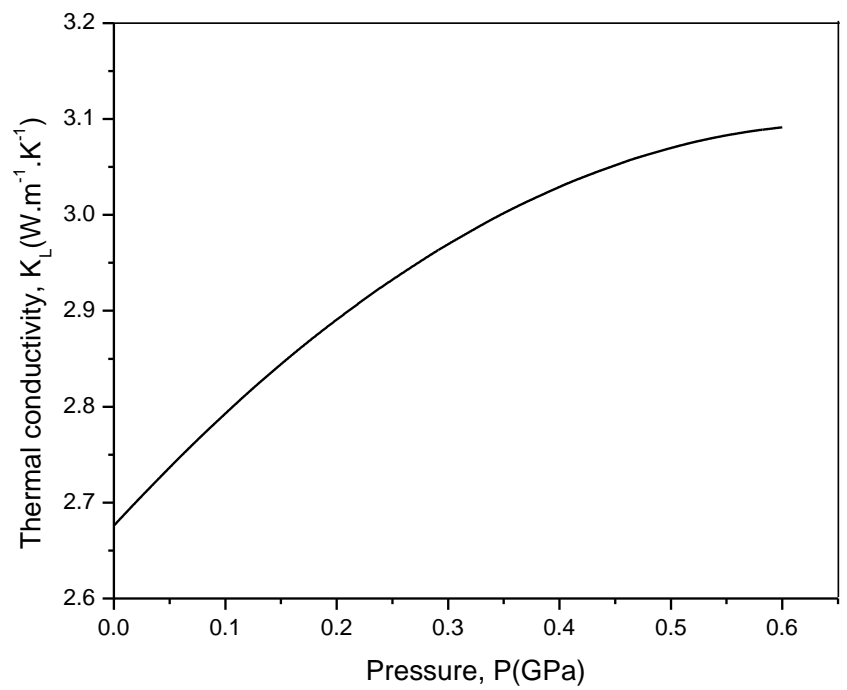

Figure 14. Variation of thermal conductivity, $K_{\mathrm{L}}$ of gabbro as a function of pressure. 


\section{SAYYADUL ARAFIN AND RAM N. SINGH}

The thermal conductivity $K_{\mathrm{L}}$ and diffusivity $D$ of gabbro as a function of pressure are plotted in Figures 14 and 15. Both $K_{\mathrm{L}}$ and $D$ increase with increasing $P$. Like $d \Theta_{D} / d P$, the gradients $d K_{L} / d P$ and $d D / d P$ are large at lower pressures and decrease as $\mathrm{P}$ increases. $K_{\mathrm{L}}$ and $D$ increase by $10 \%$ and $61 \%$ respectively as $P$ increases to $0.6 \mathrm{GPa}$ from $0 \mathrm{GPa}$.

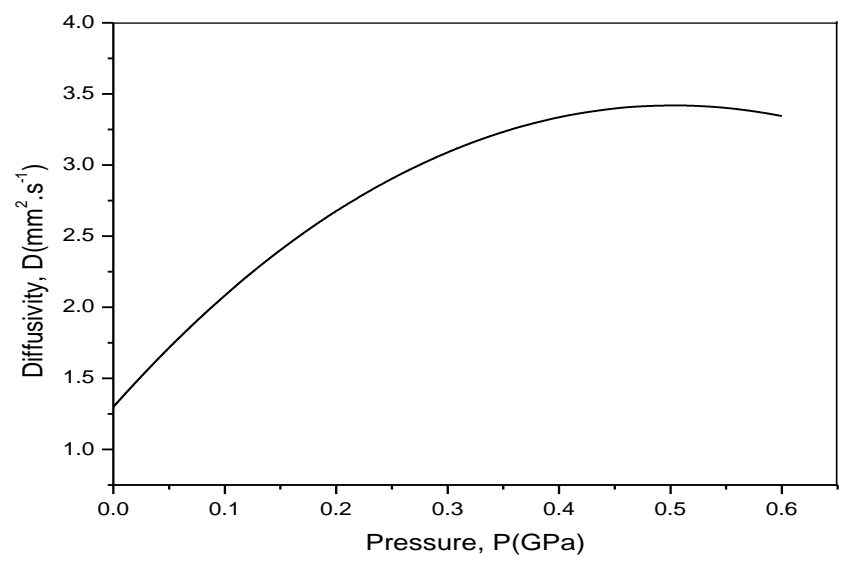

Figure 15. Diffusivity, $D$ of gabbro as a function of pressure.

\section{Conclusion}

The seismic velocities and the density data are used to determine the temperature dependence of Debye temperature, $\left(\Theta_{D}\right)$ and other thermodynamic and thermoelastic functions, such as specific heat capacity $\left(c_{P}\right.$ and $\left.c_{V}\right)$, compressibilities $\left(\kappa_{S}\right.$ and $\left.\kappa_{T}\right)$, thermal conductivity $\left(K_{\mathrm{L}}\right)$, and the diffusivity $(D)$ of gabbro and harzburgite. $\Theta_{D}$ as determined here, was further used to compute the melting temperature $T_{\mathrm{m}}$ and the viscosity $(\eta)$. The availability of experimental data for the seismic wave velocities [25] for gabbro over a wide pressure range of 0 to $6 \mathrm{kbar}$ has made it possible to also compute the pressure dependence of $\Theta_{D}, c_{V}, \kappa_{S} . K_{L}$ and $D$ of gabbro.

$\Theta_{D}$ computed at ambient conditions for gabbro is $548 \mathrm{~K}$ and for harzburgite is $693 \mathrm{~K}$. $\Theta_{D}$ for harzburgite is about $26 \%$ higher than that of gabbro. $\Theta_{D}$ for both rocks falls linearly with increasing temperature. The specific heat ratio $(\gamma)$ for gabbro and harzburgite at normal $P$ and $T$ are found to be around 1.009 and 1.0103 respectively. This value of $\gamma$ is consistent with the observation [21] that $\gamma$ is nearly unity for rocks and minerals. $\gamma$ is found to depend weakly on $T$.

The value of $\gamma$ has been utilized to calculate the specific heat capacities, $c_{P}$ and $c_{V}$, through thermodynamic relations. The values of $c_{P}$ and $c_{V}$ for gabbro are found to be $14.33 \mathrm{~J} \mathrm{~mol}^{-1} \mathrm{~K}^{-1}$ and $14.20 \mathrm{~J} \mathrm{~mol}^{-1} \mathrm{~K}^{-1}$ respectively at room temperature, $293.15 \mathrm{~K}$. Additionally, we have estimated $c_{V}$ from Debye theory where $\Theta_{D}$ occurs as an input. The value of $c_{V}$ at room temperature is obtained as $21.12 \mathrm{~J} \mathrm{~mol}^{-1} \mathrm{~K}^{-1}$ and the $c_{P}$ as $21.31 \mathrm{~J} \mathrm{~mol}^{-1} \mathrm{~K}^{-1}$. It may be noted that $c_{P}$ and $c_{\mathrm{V}}$ of gabbro determined from thermodynamic relation is about $33 \%$ lower than that determined from Debye theory. $c_{P}$ and $c_{V}$ values for harzburgite determined from thermodynamic relation are $16.71 \mathrm{~J} \mathrm{~mol}^{-1} \mathrm{~K}^{-1}$ and $16.54 \mathrm{~J}$ $\mathrm{mol}^{-1} \mathrm{~K}^{-1}$ and those determined from Debye theory are $19.31 \mathrm{~J} \mathrm{~mol}^{-1} \mathrm{~K}^{-1}$ and $19.11 \mathrm{~J} \mathrm{~mol}^{-1} \mathrm{~K}^{-1}$ respectively. In this case, specific heat capacity determined from thermodynamic relations is $13 \%$ lower than that computed from Debye theory. Specific heat capacities are found to increase with increasing temperature. The crucial criterion for determining [2] whether or not a polyatomic solid is a Debye-like solid is the closeness between the thermodynamic value of $c_{V}$ and its value calculated from Debye theory. These values exhibit little or no closeness indicating that the gabbro and harzburgite of the Oman ophiolite suite are not Debye-like solids.

Melting point has been calculated from modified Lindemann's formula by making use of Debye temperature as input. $T_{\mathrm{m}}$ of harzburgite at ambient conditions is found to be $1693 \mathrm{~K}$ compared to $1201 \mathrm{~K}$ for gabbro. It may be noted that $T_{\mathrm{m}}$ for harzburgite is about $40 \%$ higher than that of gabbro. The computed value of viscosity of molten gabbro $(0.00221 \mathrm{mPa} \mathrm{s})$ is smaller than that of the molten harzburgite $(0.00263 \mathrm{mPa} \mathrm{s})$ by about $16 \%$. We may recall that $\mathrm{Mg}, \mathrm{Fe}$ and $\mathrm{Si}$ are the main constituent elements of these rocks. It is interesting to observe that the viscosities of these rocks fall within the range of the experimental values [30] of viscosity of $\mathrm{Mg}(1.25 \mathrm{mPa} \mathrm{s}), \mathrm{Fe}(5.5$ $\mathrm{mPa} \mathrm{s}$ ) and $\mathrm{Si}(0.94 \mathrm{mPa} \mathrm{s})$.

The pressure dependence of $\Theta_{D}, c_{V}, \kappa_{S}, \kappa_{S}, K_{L}$ and $D$ for gabbro have been computed as a function of pressure. This was possible by virtue of available experimental seismic velocity data for gabbro. The computed value of $\Theta_{D}, K_{\mathrm{L}}$ and $D$ are found to increase with increasing $P$, unlike their temperature dependence. However, specific heat ( $\mathrm{c}_{\mathrm{V}}$ ) and compressibilities $\left(\kappa_{S}\right.$ and $\kappa_{T}$ ) of gabbro decrease with increasing pressure. $\Theta_{D}, T_{\mathrm{m}}, \eta, c_{V}, \kappa_{S}, \kappa_{T}$, and $D$ are smaller in mafic rocks (gabbro) than those of ultramafic rocks (harzburgite) except for the thermal conductivity, $K_{L}$. This behavior indicates the influence of the olivine content ( $80 \%$ in harzburgite and up to $40 \%$ in gabbro) on the thermal and transport properties of these rocks. The higher thermal conductivity of gabbro is likely to cause its solidification faster than is the case for harzburgite. 


\section{THERMAL AND TRANSPORT PROPERTIES OF MAFIC AND ULTRAMAFIC ROCKS}

\section{References}

1. Anderson, O.L. Thermoelastic properties of $\mathrm{MgSiO} 3$ perovskite using Debye approach, American Mineralogist, 1998, 83, 23-35.

2. Anderson, O.L., Isaak D.G. and Nelson, V.E. The high-pressure melting temperature of hexagonal close-packed iron determined from thermal physics, J. Phys. and Chem. Solids, 2003, 64, 2125-2131.

3. Anderson, D.L. Temperature and pressure derivatives, J. Geophys. Res., 1988, 93, 4688-4700.

4. Sternik, M. and Parlinski, K. Ab initio calculations of the stability and lattice dynamics of the post-perovskite, $J$. Phys. Chem. Solids, 2006, 67, 796-800.

5. Fujiwara, H., Ueda, Y., Awasthi, A., Krishnamurthy, N. and Garg, S.P. Thermodynamic study on refractory metal silicides, J. Phys. Chem. Solids, 2005, 66, 298-302.

6. Wei $\mathrm{Lu}$ and Baosheng Li, Thermal equation of state of $\left(\mathrm{Mg}_{0.9} \mathrm{Fe}_{0.1}\right) \mathrm{SiO}_{4}$ olivine, Phys. Earth. Planet. Inter., 2006, 157, 188-195.

7. Dergachov, A. L. and Starostin, V.I. The Debye characteristic temperature as indicator for formation and transformation conditions of rocks and ores, Ore Deposit Geology, 1981, 6, 67-75.

8. Christensen, N.I. and Smewing, J.D. Geology and seismic structure of the northern section of the Oman ophiolite, J. Geophys. Res., 1981, 86, 2545-2555.

9. Liping, B., Jianguoang, D. and Wei, L. Experimental studies of electrical conductivities and P-wave velocities of gabbro at high pressures and high temperatures, Sci. China, Ser. D Earth Sci., 2003, 46, 895.

10. Moores, E.M. and Jackson, E.D. Ophiolites and oceanic crust, Nature, 1974, 228, 837-842.

11. Coleman, R.G., Introduction to the Oman ophiolite special issue, J. Geophys. Res., 1981, 86, 2495-2496.

12. Kusky, T., Robinson, C. and El-Baz, F. Tertiary-Quaternary faulting and uplift in the northern Oman Hajar Mountains, Journal of the Geological Society, 2005, 162, 871-888, doi:10.1144/0016-764904-122 http://wmblogs.wm.edu/cmbail/dispatches-from-oman-juxtaposition/

13. Boudier, F. and Coleman, R.G. Cross-section through the peridotite in the Samail ophiolite, Southeastern Oman, J. Geophys. Res., 1981, 86, 2573-2592.

14. Korenaga, J. and Klemen, P.B., Origin of gabbro sills in the Moho transition zone of the Oman ophiolite: Implications for magma transport in the oceanic lower crust, J. Geophys. Res., 1997, 102(B12), 27,729-27,749.

15. Arafin, S., Singh, R.N. and George, A.K. Extension of Lindemann's Formula to Study the Pressure Dependence of Melting Temperature Int. J. Thermophys. 2012, 33:1013-1022, DOI 10.1007/s10765-012-1227-8S.

16. Anderson, O.L. Equations of State of Solids for Geophysics and Ceramic Science, Oxford University Press, New York, 1995

17. Anderson, O.L. Isaak, D.G. Mineral Physics and Crystallography, A Handbook of Physical Constants, AGU Reference Shelf 2, 1995, 64-97

18. Kittel, C. Introduction to Solid State Physics, ( $7^{\text {th }}$ Edition), Wiley, New York,1996.

19. Mott, N.F. and Jones, H. The Theory of the Properties of Metals and Alloys, ( $2^{\text {nd }}$ Edition). Oxford University Press, Oxford, 1936.

20. Waples, D.W. and Waples, J.S. A Review and Evaluation of Specific Heat Capacities of Rocks, Minerals, and Subsurface Fluids. Part 1: Minerals and Nonporous Rocks, Natural Resources Research, 2004, 13, 97-122.

21. Horai, K. and Simmons, G. An empirical relationship between thermal conductivity and Debye temperature for silicates, J. Geophys. Res., 1970, 75, 678.

22. Keiffer, H.H. Temperature of rock thermal properties, File=/xtex/tes/krc/HeatOfT.tex 2010feb, July 19, 2010

23. Mottaghy, D., Vosteen, H.D. and Schellschmidt, R. Temperature dependence of the relationship of thermal diffusivity versus thermal conductivity for crystalline rocks. Int. J. Earth Sci, 2008, 97(2), 435-442. DOI 10.1007/s00531-007-0238-3.

24. Gibert, B., Seipold, U., Tommasi, A. and Mainprice, D. Thermal diffusivity of upper mantle rocks: Influence of temperature, pressure, and the deformation fabric, J. Geophys. Res., 2003, $108: 2359$.

25. Lindemann, F.A. Uber die Berechnung molecularer Eigenfrequenzen, 1910, Phys. Z. 11, 609-612.

26. Faber, T.E., Introduction to Theory of Liquid Metals, Cambridge University Press, Cambridge, 1972.

27. Andrade E.N. A theory of the viscosity of liquids, Phil. Mag., 1934, $17: 497$

28. Iida, T. and Guthrie, R.I.L. The Physical Properties of Liquid Metals, Clarendon Press, Oxford, 1988.

29. Anderson, D.L, Theory of the Earth, Caltech Books, Caltech, Pasadena,1989.

30. Brandes, E.A. and Brook, G.B. (Edited), Smithshells Metals Reference Book ( $7^{\text {th }}$ Edition), ButterworthHeinemann, Oxford, 1992

Received 6 December 2015

Accepted 29 February 2016 